\title{
TO COMPARE ROSUVASTATIN WITH ATORVASTATIN IN TERMS OF MEAN CHANGE IN LDL-C IN PATIENT OF DIABETES MELLITUS.
}

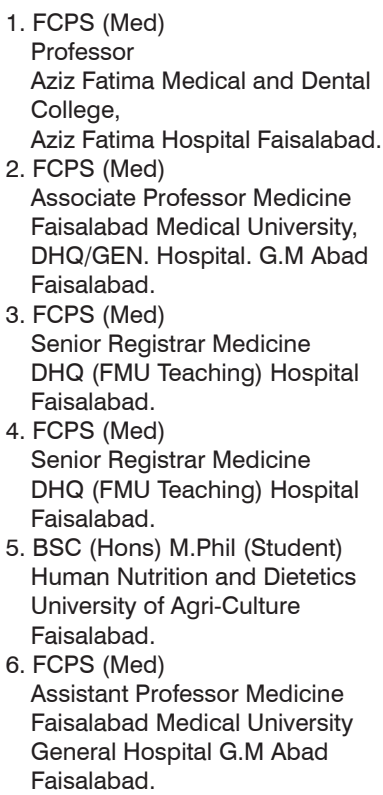

Correspondence Address:

Prof. Dr. Masood Javed

Aziz Fatima Medical and Dental

College,

Aziz Fatima Hospital Faisalabad.

dilshaddoctor@yahoo.com

Article received on:

03/02/2020

Accepted for publication:

22/04/2020

\begin{abstract}
Masood Javed ${ }^{1}$, Dilshad Mohammad², Muzzammal Iftikharr ${ }^{3}$, Mohsin Jameel $^{4}$, Zain Masood ${ }^{5}$, Nazir Ahmed ${ }^{6}$

ABSTRACT: Diabetes Mellitus is a very common metabolic disorder characterized by hyperglycemia and altered metabolism of lipids, proteins and carbohydrates due to absolute or relative insulin deficiency or insulin resistance. There is a close association between complications of Diabetes and Diabetic Dyslipidemias. The lowering of LDL levels with statins varies from 20 to $60 \%$ and greatest effects are seen with the most potent statins such as Atorvastatin, and Rosuvastatin in higher doses. Objectives: The objective of the study was; to compare Rosuvastatin with Atorvastatin in terms of mean change in LDL-C in patients of Diabetes Mellitus. Study Design: Randomized Control Trail. Setting: Department of Medicine DHQ Hospital, Faisalabad. Period: Six months from 01/10/2018 to 31/03/2019. Material \& Methods: Results: A total of 160 cases ( 80 in each group) fulfilling the inclusive/exclusive criteria were enrolled to compare Rosuvastatin with Atorvastatin in terms of mean change in LDL-C in patients of Diabetes Mellitus. Mean LDL-C levels at baseline was recorded as $159.61+1.22$ in Group-A and 159.51+1.21 in Group-B, p value was calculated as 0.603 showing insignificant difference. Mean LDL-C after 6 weeks of treatment was recorded as $129.11 p+1.50$ in Group-A and $129.89+2.23$ in Group-B, p value was calculated as 0.01 showing significant difference. Mean change in LDL-C level after 6 weeks of treatment was recorded as $30.5+1.88$ in Group-A and $29.63+2.57$ in Group-B, p value was calculated as 0.01 showing a significant difference. The data was stratified for Age, Gender, Duration of Diabetes Mellitus and control of Diabetes Mellitus. Conclusion: This study proves superiority of Rosuvastain over Atorvastatin in reducing LDL-C level in type 2 DM Patients.
\end{abstract}

Key word: $\quad$ Atorvastatin, Diabetes Mellitus, Hyperglycemia, Insulin Deficiency and Resistance, LDL-C, Rosuvastain.

Article Citation: Javed M, Iftikhar M, Mohammad D, Jameel M, Masood Z, Ahmed N. To compare Rosuvastatin with Atorvastatin in terms of mean change in LDL-C in patient of Diabetes Mellitus. Professional Med J 2020; 27(7):1505-1510. DOI: 10.29309/TPMJ/2020.27.07.4538

\section{INTRODUCTION}

Diabetes, Smoking, Hypertension and Hypercholestremia are well established risk factors for the development of coronary artery disease..$^{1,2}$ Hypercholestremia is a major contributor of Cardio Vascular Disease in both developed and developing worlds. In patients with Diabetes lipid abnormalities play an important role in the development of Atherogenesis, therefore lowering serum cholesterol and LDL cholesterol concentration reduces the risk of Cardiovascular events including MI, Stroke, Coronary revascularization and Death. ${ }^{3,4}$

Therapeutic life style adjustment is very helpful in managing familial hypercholestremia. ${ }^{5}$ Lifestyle modification includes modification in Diet, exercise, reduction in Alcohol consumption and withdrawal of tobacco products. Regarding pharmacological therapy, statins are the first line drugs in LDL- cholesterol reduction and their clinical use has significantly contributed to the prevention and treatment of Atherosclerosis in Cardiovascular diseases. However different statins have different effect in this regard and their doses also differ to reach same level of LDL-C. In patients of CAD use of synthetic statins such as Rosuvastatin and Atorvastatin is beneficial and they are prescribed commonly. In addition to this they also have other pleotropic effects 
such as modification in endothelial funcation, inflammatory response, stability of plague and formation of the thrombus.

Rosuvastatin is an HMGR Antagonist which competes with endogenous substrate for the site of activity of the enzyme. Multiple clinical trials have demonstrated that both Rosuvastatin and Atorvastatin are effective \& safe in reducing fatal and non-fatal CV events. Use of Rosuvastatin causes more reduction in LDL-C in Western population; however the response may be different in Asians as compared with Whites due to genetic differences. According to FDA recommendations Asian patients may be started with $5 \mathrm{mg}$ daily Rosuvastatin and $10 \mathrm{mg}$ daily Atorvastatin.

The STELLAR Trial by Jone PH et al, comparing Rosuvastatin with Atorvastatin, revealed that Rosuvastatin produced significant reduction in LDL-C levels ${ }^{11}$ as compared to Atorvastatin. In the LISTEN trial by Arshad et al. 10mg of Atorvastatin was compared with $5 \mathrm{mg}$ Rosuvastatin.

The previous comparison between these two statins, in patients of raised LDL, shows $0.54 \pm$ 0.88 reduction in LDL level with atorvastatin as compared to Rosuvastatin which shows $0.96 \pm$ 0.96 reduction in LDL-C.

This study will further explore the reduction in LDL_C and its magnitude, in patients with Hypercholestremia by Rosuvastatin as compared with Atorvastatin, and it will help us in modifying our treatment regimes in such cases so that we may manage these patients more appropriately and cost effectively.

\section{MATERIAL \& METHODS}

Study Design it was a Randomized Control trail contucted at Department of Medicine DHQ Hospital, Faisalabad.

Total duration of study was 6 months from $01 / 10 / 2018$ to $31 / 03 / 2019$. Each patient was evaluated after 6 weeks of statin therapy.

\section{Sample Size}

By using WHO sample calculator for two means:

- Anticipated population means $=0.54$

- Test value of population mean $=0.96$

- Pooled standard deviation $\quad=0.92$

- Power of study

- Level of signification

- Sample size each group)

$=80 \%$

$=5 \%$

$=160(80$ in

Conservative Non-probability sampleing technique was used.

Inclusion Criteria

Diabetic out patients of either gender between 40 to 80 years of age.

Patients with the history of type 2 DM for two years.

Patients with raised LDL-C at single reading.

\section{Exclusion Criteria}

Subjects with significant Liver or Renal impairment. Subjects with myopathy (pain and weakness of muscles, raised CPK level $>200 \mathrm{mcg} / \mathrm{L}$ ).

Permission was taken from ethical committee of hospital before the start of study and informed consent was taken from all the participants of study. Randomization was done by computer generated number table to allocate patients in either Group-A(Rosuvastatin) or Group$B$ (Atorvastatin).patients were instructed to take study medication at the bed time with a glass of water for up to six weeks. Group A was given $10 \mathrm{mg}$ of Rosuvastatin and group B was given $20 \mathrm{mg}$ Atorvastatin daily.

Baseline LDL-C level was recorded at the start of the study and patients were advised to take medications for six weeks. After six weeks LDL-C levels were done in hospital lab and verified by pathologist. Patients were followed up by keeping telephonic contact. All data was entered in specially designed Performa by me.

All data was entered and analyzed according to SPSS (Statistical Package for social studies) version12.0.Mean and standard deviation was calculated for age, LDL-C level at baseline 
and 6 weeks and change in levels. Frequency and percentages were calculated for gender. Independent test was used to compare mean change in LDL-C between two groups. A p-value of $\leq 0.05$ was considered significant. Effect modifiers like Age, Gender, Duration of DM, Type and control of DM was stratified and post stratification t-test was applied.

\section{RESULTS}

A total of 160 cases (80 in each group) fulfilling the Inclusive/Exclusive criteria were enrolled to compare Rosuvastatin with Atorvastatin in terms of mean change in LDL-C in patients of Diabetes Mellitus.

Regarding Age of the patients study shows that $32.5 \%(n=26)$ in group $A$ and $35 \%(n=28)$ in group $B$ were between 40 to 46 years of age while $67.5 \%(n=54)$ in group $A$ and $65 \%(n=52)$ in group $B$ was between 61 to 80 years of age mean difference was calculated as $54.3 \pm 7.54$ in group $A$ and $503.84 \pm 7.38$ years in group B. (Table-I).

\begin{tabular}{|l|c|c|c|c|}
\hline $\begin{array}{c}\text { Age } \\
\text { (in years) }\end{array}$ & \multicolumn{2}{|c|}{$\begin{array}{c}\text { Group-A } \\
(\mathbf{n = 8 0}\end{array}$} & \multicolumn{2}{c|}{$\begin{array}{c}\text { Group-B } \\
\text { (n=8) }\end{array}$} \\
\hline & $\begin{array}{c}\text { No. of } \\
\text { patients }\end{array}$ & $\%$ & $\begin{array}{c}\text { No. of } \\
\text { patients }\end{array}$ & $\%$ \\
\hline $40-60$ & 26 & 32.5 & 28 & 35 \\
\hline $61-80$ & 54 & 67.5 & 52 & 65 \\
\hline Total & 80 & 100 & 80 & 100 \\
\hline Mean+SD & $54.32+7.54$ & \multicolumn{2}{|c|}{$53.84+7.38$} \\
\hline
\end{tabular}

According to Gender $57.5 \%(n=46)$ in group A and $52.5 \%(n=42)$ in group $B$ were Male while $42.5 \%(n=34)$ in group $A$ and $47.5 \%(n=38)$ in group B were Female patients. (Table-II).

\begin{tabular}{|l|c|c|c|c|}
\hline \multirow{2}{*}{ Gender } & \multicolumn{2}{|c|}{$\begin{array}{c}\text { Group-A } \\
(\mathbf{n = 8 0 )}\end{array}$} & \multicolumn{2}{c|}{$\begin{array}{c}\text { Group-B } \\
(\mathbf{n = 8 0 )}\end{array}$} \\
\cline { 2 - 5 } & $\begin{array}{c}\text { No. of } \\
\text { patients }\end{array}$ & $\%$ & $\begin{array}{c}\text { No. of } \\
\text { patients }\end{array}$ & $\%$ \\
\hline Male & 46 & 57.5 & 42 & 52.5 \\
\hline Female & 34 & 42.5 & 38 & 47.5 \\
\hline Total & 80 & 100 & 80 & 100 \\
\hline
\end{tabular}

Table-II. Gender Distribution. ( $\mathrm{N}=160)$.
Mean LDL-C levels at baseline was recorded as 159.61+1.22 in Group-A and 159.51+1.21 in Group-B, p-value was calculated as 0.603 showing insignificant difference. (Table-III).

\begin{tabular}{|c|c|c|c|c|}
\hline \multirow{3}{*}{ LDL-C } & \multicolumn{2}{|c|}{$\begin{array}{c}\text { Group-A } \\
(n=80)\end{array}$} & \multicolumn{2}{|c|}{$\begin{array}{l}\text { Group-B } \\
(n=80)\end{array}$} \\
\hline & Mean & SD & Mean & SD \\
\hline & 159.61 & 1.22 & 159.51 & 1.21 \\
\hline
\end{tabular}

Mean LDL-C after 6 weeks of treatment was recorded as129.11p+1.50 in Group-A and $129.89+2.23$ in Group-B, $p$ value was calculated as 0.01 showing significant difference (Table-IV).

\begin{tabular}{|c|c|c|c|c|}
\hline \multirow{3}{*}{ LDL-C } & \multicolumn{2}{|c|}{$\begin{array}{c}\text { Group-A } \\
(n=80)\end{array}$} & \multicolumn{2}{|c|}{$\begin{array}{c}\text { Group-B } \\
(n=80)\end{array}$} \\
\hline & Mean & SD & Mean & SD \\
\hline & 129.11 & 1.50 & 129.89 & 2.23 \\
\hline
\end{tabular}

Mean change in LDL-C level after 6 weeks of treatment was recorded as $30.5+1.88$ in Group-A and 29.63+2.57 in Group-B, p-value was calculated as 0.01 showing a significant difference. (Table-V).

\begin{tabular}{|c|c|c|c|c|}
\hline \multirow{3}{*}{ LDL-C } & \multicolumn{2}{|c|}{$\begin{array}{l}\text { Group-A } \\
(n=80)\end{array}$} & \multicolumn{2}{|c|}{$\begin{array}{l}\text { Group-B } \\
(n=80)\end{array}$} \\
\hline & Mean & SD & Mean & SD \\
\hline & 30.5 & 1.88 & 29.63 & 2.57 \\
\hline
\end{tabular}

The data was stratified for age, gender, duration of diabetes mellitus and control of diabetes mellitus. (Table-VI to IX). 


\begin{tabular}{|c|c|c|c|c|}
\hline \multirow{6}{*}{ LDL-C } & \multicolumn{2}{|c|}{$\begin{array}{c}\text { Group-A } \\
(n=80)\end{array}$} & \multicolumn{2}{|c|}{$\begin{array}{c}\text { Group-B } \\
(n=80)\end{array}$} \\
\hline & Mean & SD & Mean & SD \\
\hline & \multicolumn{4}{|c|}{$40-60$ years } \\
\hline & 29.56 & 1.27 & 29.97 & 2.34 \\
\hline & \multicolumn{4}{|c|}{$61-80$ years } \\
\hline & 30.3 & 1.52 & 29.41 & 2.11 \\
\hline
\end{tabular}

Table-VI. Stratification for mean change in LDL-C levels after 6 weeks of treatment with regards to age. $(n=160)$ 40-60 years. P-value: 0.01

\begin{tabular}{|c|c|c|c|c|}
\hline \multirow{6}{*}{ LDL-C } & \multicolumn{2}{|c|}{$\begin{array}{c}\text { Group-A } \\
(n=80)\end{array}$} & \multicolumn{2}{|c|}{$\begin{array}{c}\text { Group-B } \\
(n=80)\end{array}$} \\
\hline & \multicolumn{4}{|c|}{ Male } \\
\hline & Mean & SD & Mean & SD \\
\hline & 28.99 & 1.04 & 29.44 & 2.09 \\
\hline & \multicolumn{4}{|c|}{ Female } \\
\hline & 29.55 & 1.47 & 30.48 & 2.16 \\
\hline
\end{tabular}

Table-VII. Stratification for mean change in LDL-C levels after 6 weeks of treatment with regards to gender. $(n=160)$.

$P$ value: $0.01, \quad P$ value: 0.00

\begin{tabular}{|c|c|c|c|c|}
\hline \multirow{6}{*}{ LDL-C } & \multicolumn{2}{|c|}{$\begin{array}{c}\text { Group-A } \\
(n=80)\end{array}$} & \multicolumn{2}{|c|}{$\begin{array}{c}\text { Group-B } \\
(n=80)\end{array}$} \\
\hline & Mean & SD & Mean & SD \\
\hline & \multicolumn{4}{|c|}{ 0-1 Year } \\
\hline & 29.41 & 1.19 & 30.51 & 2.14 \\
\hline & \multicolumn{4}{|c|}{ 1-2 Year } \\
\hline & 29.47 & 1.25 & 29.97 & 2.20 \\
\hline
\end{tabular}

Table-VIII. Stratification for mean change in Idl-c levels after 6 weeks of treatment with regards to duration of diabetes mellitus. $(n=160)$.

$P$ value: 0.00 , $P$ value: 0.02

\begin{tabular}{|l|c|c|c|c|}
\hline \multirow{4}{*}{} & \multicolumn{2}{|c|}{$\begin{array}{c}\text { Group-A } \\
(\mathbf{n = 8 0 )}\end{array}$} & \multicolumn{2}{c|}{$\begin{array}{c}\text { Group-B } \\
(\mathbf{n = 8 0 )}\end{array}$} \\
\hline \multirow{3}{*}{ LDL-C } & Mean & SD & Mean & SD \\
\hline & \multicolumn{4}{|c|}{ Controlled } \\
\hline & 28.41 & 1.06 & 29.49 & 2.23 \\
\hline & \multicolumn{4}{|c|}{ Uncontrolled } \\
\hline & 29.55 & 1.47 & 30.48 & 2.16 \\
\hline
\end{tabular}

TABLE-IX. Stratification for mean change in LDL-C levels after 6 weeks of treatment with regards to control of diabetes mellitus $(n=160)$.

$P$ value: $0.00, P$ value: 0.00

\section{DISCUSSION}

In Diabetes Mellitus relative deficiency, complete absence or resistance of insulin leads to hyperglycemia and certain changes in lipid, protein \& carbohydrate metabolism. Due to this Diabetes Mellitus is considered to be a metabolic disorder. ${ }^{8,12}$ Complications of Diabetes are closely associated with Dyslipidemias which are responsible for approximately $80 \%$ of Diabetic deaths. ${ }^{13}$ Dose of different statins for treating dyslipidemias is variable ${ }^{14,15}$, and the decrease in LDL-C levels varies between $20 \%$ and $60 \%$. It is also suggested that statins such as Rosuvastatin \& Atorvastatin are more potent but at high doses.

Evidence is lacking regarding their superiority over each other ${ }^{16,17}$, This study was done with the objective that reduction in LDL-C in patients with Hypercholestremia with Rosuvastatin as compared with Atorvastatin may be explored as this may help us in modifying our treatment regimens for reducing the LDL-C.

The previous comparison of Rosuvastatin and Atorvastatin in patients of raised LDL shows $0.54 \pm 0.88$ reductions in LDL-C level with Atorvastatin as compared to Rosuvastatin which shows $0.96 \pm 0.96$ reductions in LDL-C from the base line. ${ }^{8}$ These findings support results of our study that Rosuvastatin is more effective in decreasing LDL-C as compare to Atorvastatin. ( 0.87 with Rosuvastatin as compare to 0.42 with Atorvastatin).

Wolffen buttel $\mathrm{BH}$ et all ${ }^{17}$ in their study compared the cholesterol lowering effect of, Rosuvastatin with Atorvastatin in type 2 Diabetics. They recorded that base line LDL-C in the RSV and ATV groups was $4.23+/-0.98 \mathrm{mmol}$ and $4.43+/-0.99$, whilst apoB/apoA1 was $0.86+/-0.22$ and $0.92+/-0.35$, respectively. A greater reduction in apoB/apoA1 was seen with $\operatorname{RSV}(-34.9 \%,-39.2 \%$ and $-40.5 \%)$ than with ATV(-32.4\%,-34.7\% and $-35.8 \%, P<0.05$ at weeks 12,16 and 18).According to American Diabetes Association(ADA) guidelines LDL-C goal of $<2.6 \mathrm{mmol} / \mathrm{l}(-1)$ was reached by $82 \%, 84 \%$ and $92 \%$ of patients with RSV and $74 \%, 79 \%$ and $81 \%$ with ATV. Reduction in Triglyceride was comparable in both groups of treatment and ranged between $16-24 \%$.In addition to this both modes of treatment were well tolerated and only 9 and 11 patients respectively stopped treatment 
due to side effects. Overall Wolffen buttel $\mathrm{BH}$ et al concluded that Rosuvastatin showed more improvement in lipid profile as compare \& Atorvastatin.

Another study, URANUS ${ }^{18}$ done by Berne A and Siewert-Delle, also compared the same effect of statins on lipid profile in patient with type 2 Diabetes Mellitus and they found that Rosuvastain had greater lowering effect on LDL-C level during fixed dose and titration periods $(p<0.0001)$. In their study Berne $A$ and Siewert-Delle demonstrated that more patients, $81 \%$ vs $65 \%(p<0.001)$ at 4 weeks of treatment and $94 \%$ vs $88 \%$ ( $p$ 0.05) at 10 weeks of treatment, achieved their LDL-C goal with Rosuvastatin as compared with Atorvastatin. Furthermore patients receiving Rosuvastatin showed a less dose titration and continued with their starting dose. Considering 2003-European LDL-C goal (2.5 mmol/L) more patients on Rosuvastatin than on Atorvastatin achieved this goal, i.e. $65 \%$ vs. $33 \%(p<0.0001) .{ }^{18}$

Moreover both drugs were well tolerated by the patients as there were no significant safety concerns and in view of all these facts was concluded that Rosuvastatin is more effective than Atorvastatin in achieving the LDL-C goal in type 2 Diabetic patients.

Peter H. Jones and others ${ }^{11}$ compared Rosuvastain with Atorvastatin, Pravastatin and simvastatin across dose Ranges for reduction of LDL cholesterol and recorded that Rosuvastatin has greater effect in reduction of total cholesterol when compared with other competitors. Also it has more effect in reducing Triglyceride as compared to simvastatin and pravastatin. Besides this HDL-C was increased by $7.7 \%-9.6 \%$ with Rosuvastatin as compared with2.1-6.8\% with Atorvastatin. Adult treatment panel $111 \mathrm{LDL}$ cholesterol goals were achieved by $82 \%$ to $89 \%$ of patients treated with Rosuvastatin 10 to $40 \mathrm{mg}$ compared with $69 \%$ to $85 \%$ of patients treated with atorvastatin 10 to $80 \mathrm{mg}$ : the European LDL cholesterol goal of less than $3 \mathrm{mmol} / \mathrm{L}$ was achieved by $79 \%$ to $92 \%$ in Rosuvastatin groups compared with $52 \%$ to $81 \%$ in Atorvastatin groups. Drug tolerability was similar across treatments.
In August 2003 the United States food and drug administration FDA approved Rosuvastatin calcium(Crestor; AstraZeneca Pharmaceutical ,Wilmington, DE) as an adjunct to diet in patients with primary Hypercholestremia, Mixed Dyslipidemia or Fredrickson type 4 for hypercholesterolemia. In addition to this Rosuvastatin is also proved for use as an adjunct to other lipids lowering treatments in patients with Homozygous or Heterozygous familial Hypercholesterolemia.

In light of the above discussion and comparison our hypothesis that, Rosuvastatin is better in reducing LDL-C as compared to Atorvastatin in patients of Type 2 Diabetes Mellitus, is justified. Although results of our study are quite clear and substantial helping us in modifying the treatment for reducing the LDL $\mathrm{C}$ however more trials are required to further validate these effects.

\section{CONCLUSION}

Our study concludes that Rosuvastatin is significantly more effective in reducing LDL-C in patients of diabetes mellitus.

\section{Copyright $\subset 22$ Apr, 2020.}

\section{REFERENCES}

1. Castellanos-Jankiewicz A, Del, Bosque-Plata L, Tejero ME. Combined effect of sterol and dietary fiber for the treatment of hypercholesterolemia. Plant Foods Hum Nutr. 2014; 69:93-100.

2. Noto D, Cefalu AB, Averna MR. Beyond statins: New lipid lowering strategies to reduce cardiovascular risk. Curr Atheroscler Rep. 2014; 16:414.

3. Varghese MJ. Familial hypercholesterolemia: A review. Ann Pediatr Cardiol. 2014; 7:107-17.

4. Ogawa H, Mastsui K, Saito Y, Sugiyama S, Jinnouchi H, Sugawara M, et al. Differences between Rosuvastatin and Atorvastatin in lipid lowering action and effect on glucose metabolism in Japanese Hypercholestremia patients with concurrent diabetes. Circulation.2014; 78(10):2512-5. 
5. Odeberg J, Freitaq M, Forssell H, Vaara I, Person ML, Odeberg $H$, et al. The influence of smoking and impaired glucose homeostasis on the outcome in patients presenting with an acute coronary syndrome: A cross-sectional study. BMJ Open. 2014; 4:e005077.

6. Xilifu D, Abudula A, Rehemu N, Zhao L, Zhou X. Effect of Rosuvastatin on hyperuricemic rats and the protective effect on endothelial dysfunction. Exp Ther Med. 2014; 8:1683-8.

7. Kim JW, Yun KH, Kim EK, Kim YC, Joe D, Ko JS. Effect of high dose Rosuvastatin loading before primary percutaneous coronary intervention on infarct size in patients with ST-segment elevation myocardial infarction. Korean Circ J. 2014; 44:76-81.

8. Arshad AR. Comparison of low-dose Rosuvastatin in lipid-lowering efficacy and safety in a high risk Pakistani Cohort: an open label randomized trial. J Lipids. 2014:875-907.

9. FDA. Information for Healthcare Professionals: Crestor (Rosuvastatin Calcium). 2016. Available at:http://www.fda.gov/Drugs/DrugSafety/PostmarketDrugSafetylnformationforPatientsandProviders/ ucml24906.htm. [Accessed 16 Nov.2016.

10. FDA. Lipitor (atorvastatin calcium) tablets prescription information. 2015. Available at:http://www.accessdata. fda.gov/drugsatfda_docs/label/2015/020702s065lbl. pdf.Accessed 16 Nov. 2016.

11. Jones $\mathrm{PH}$, Davidson $\mathrm{MH}$, Stein $\mathrm{EA}$, Bays $\mathrm{HE}, \mathrm{Mc}$ Kenney JM. Comparison of the Efficacy and Safety of Rosuvastatin versus Atorvastatin, Simvastatin, and Pravastatin across Doses (STELLAR* Trial). Am J Cardiol 2003; 93:152-60.
12. Patlak M. New weapons to combat an ancient disease: Treating diabetes. FASEB J 2002. Dec; 16(14):1853.

13. Abdul-Ghani MA, Matsuda M, Jani R. The relationship between fasting hyperglycemia and insulin secretion in subjects with normal or impaired glucose tolerance. Am J Physiol Endocrinol Metab. 2008; 295:E401E406 Global burden of diabetes. International Diabetes federation. Diabetic atlas fifth edition 2011, Brussels. Available at http://www.idf.org/diabetesatlas (Accessed 18th December 2011).

14. Chamnan P, Simmons RK, Forouhi NG, Luben R. Khaw $\mathrm{Ky}$, Wareham NJ et al. Incidence of type 2 diabetes using proposed HbA1c diagnostic criteria in the EPIC-Norflok cohort: Implication for preventive strategies. Available at http://care.diabetesjournal. org (Accessed 19th December 2011).

15. Kashyapa $\mathrm{H}$ et al. Comparison of efficacy and safety of Rosuvastatin versus atorvastatin in reduction of low density lipoprotein cholesterol in patients of type 2 diabetes mellitus with dyslipidemia. Int $\mathrm{J}$ Res Med Sci.2018 Aug; 6(8)2671-2676.

16. Mbanya JC. The burden of type 2 diabetes mellitus in the African diaspora. Available at www.medscape. com/view article/560718_2.

17. Wolffen buttel $B H$, Franken $A A$, Vincent $H H$, Dutch Corall Study Group. Cholesterol-lowering effects of Rosuvastatin compared with atorvastatin in patients with type 2 diabetes -- CORALL study. J Intern Med. 2005; 257(6):531-9.

18. Berne C, Siewert-Delle A, the URANUS study investigators. Comparison of Rosuvastatin and atorvastatin for lipid lowering in patients with type 2 diabetes mellitus: Results from the URANUS study. Cardiovascular Diabetology 2005; 4:7.

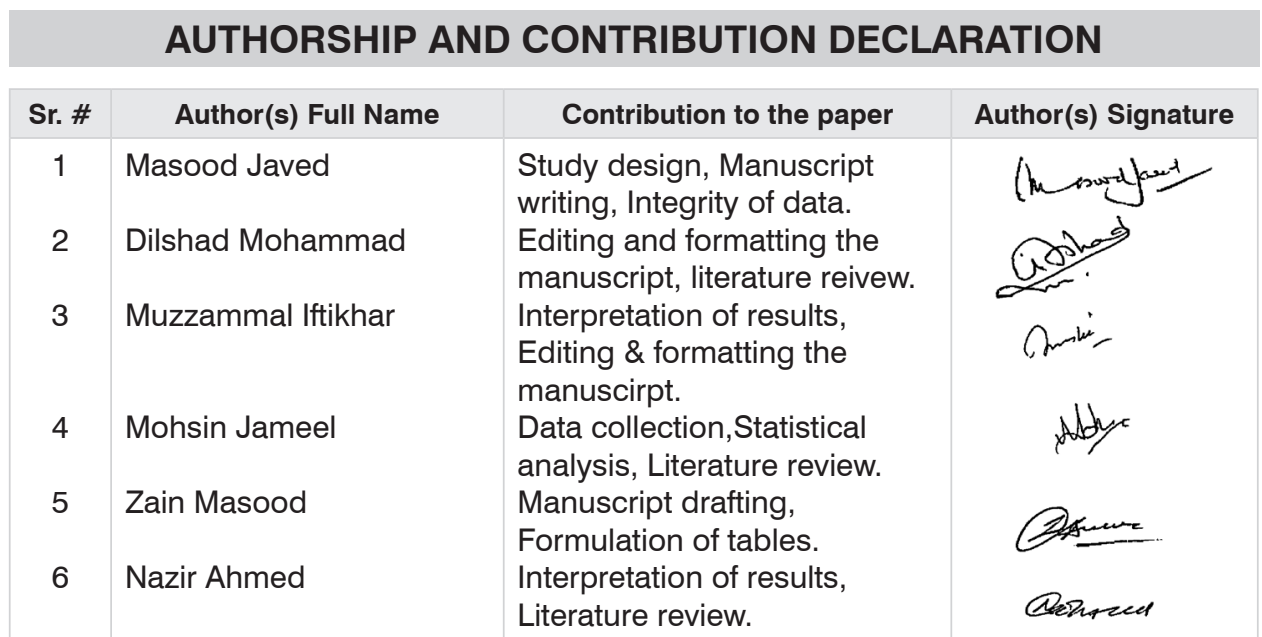

